\title{
ARTÍCULO
}

\section{Sobre la responsabilidad (ambiental) en la tradición occidental a partir del pensamiento de Nietzsche y Agamben. Una crítica a la noción de "soberanía"•}

\section{On (environmental) responsibility in western tradition from Nietzsche's and Agamben's thought. A critique of the notion of "sovereignty"}

\author{
Juan Ramón Fallada-García-Valle \\ Universitat Rovira i Virgili
}

Fecha de recepción 09/10/2019 | De aceptación: 31/03/2020 | De publicación: 15/06/2020

\section{RESUMEN}

A partir de las reflexiones de Nietzsche en torno al pensamiento occidental y a través de la contraposición razóninstinto (o polis-physis, domesticado-salvaje), se analiza la manera cómo se ha entendido la responsabilidad política y jurídica en sus tres dimensiones (personal, social y ambiental). El particular locus asignado a la noción de "soberanía" en nuestra tradición, a saber, en el intersticio de las contraposiciones mencionadas, lo convierte en el elemento nuclear que articula esos ámbitos de responsabilidad. Finalmente, se critica tal noción de "soberanía", subrayando los problemas que genera para la atribución de responsabilidades, particularmente en el ámbito ambiental.

PALABRAS CLAVE

responsabilidad; soberanía; polis-physis; medioambiente; Nietzsche, Agamben.

\section{ABSTRACT}

From Nietzsche's reflections on Western thought, the way in which political and legal responsibility has been understood in their three dimensions (personal, social and environmental), is analyzed through reason-instinct counterpoint (or polis-physis, domesticated-wild). The particular place assigned to the notion of "sovereignty" in our tradition, namely, in the interstice of the aforementioned counterpoint, makes sovereignty the nuclear element that articulates those areas of responsibility. Finally, this notion of "sovereignty" is criticized, underlining the problems it generates for the attribution of responsibilities, in particular the environmental ones.

\section{KEY WORDS}

responsibility, sovereignty, polis-physis, environment, Nietzsche, Agamben.

\footnotetext{
- Este artículo se ha elaborado en el marco del "PROYECTO DE I+D: La constitución climática global: gobernanza y Derecho en un contexto complejo" (CONCLIMA-DER2016-80011-P), (MINECO/FEDER, UE), Programa Estatal de Fomento de la Investigación Científica y Técnica de Excelencia, subprograma Estatal de Generación del Conocimiento, en el marco del Plan Estatal de Investigación Científica y Técnica y de Innovación 2013-2016, efectuada por resolución de 17 de junio de 2015 (BOE de 23 de junio) de la Secretaría de Estado de Investigación, Desarrollo e Innovación (SEIDI), Ministerio de Economía y Competitividad, España.”
} 
Sumario. 1. Introducción. 2. La noción de "responsabilidad" en Nietzsche. 2.1. Responsabilidad en el conflicto interno entre lo animal y lo humano. 2.2. Responsabilidad en la dimensión socio-política del conflicto entre lo animal y lo humano. El individuo soberano como individuo responsable. 2.3. El locus del individuo soberano: entre la polis y la physis. 3. Individuo soberano y homo sacer. 4. Responsabilidad ambiental. El ambiente salvaje como amenaza. 5. Conclusiones.

\section{Introducción}

Este trabajo tiene como trasfondo la problemática medioambiental actual, en particular, las dificultades para que los Estados acuerden políticas de protección ambiental serias y asuman responsabilidades (jurídicas) por los daños producidos. Con todo, las conclusiones son aplicables a otros ámbitos.

Para dar cuenta de la raíz de esas dificultades, se propone examinar las nociones de "responsabilidad" y "soberanía" a partir de la tradicional contraposición entre razón e instinto, o entre cultura y naturaleza (polis-physis), o, como aquí también se va a expresar, entre lo domesticado y lo salvaje. Esas contraposiciones se desplegarían en tres dimensiones distintas: en primer lugar, la del ser humano consigo mismo, esto es, con su animalidad o su instintividad (o su "salvajismo"); en segundo lugar, la de los seres humanos entre sí, prestando especial atención a aquella relación en que, al menos una de las partes es concebida en su salvajismo; finalmente, la del ser humano con el entorno, prestando nuevamente particular atención a la manera cómo el ser humano interactúa con los entornos indómitos, salvajes.

Esas tres dimensiones guardarían conexión entre sí. En otras palabras, la manera cómo nos hemos definido y nos hemos relacionado con nosotros mismos y con otras personas tendría su traslación en la manera cómo nos hemos relacionado con el ambiente. Así, se confía en que el examen del modo cómo nos relacionamos con nosotros mismos y con los demás genere conclusiones exportables al modo cómo nos relacionamos con el ambiente.

El orden de desarrollo del tema se basa en esa confianza de que las tres dimensiones guardan conexiones entre sí. Primeramente, se examinarán las dimensiones personal y social de la responsabilidad. Seguidamente, la noción de "responsabilidad" se enlazará con la de "soberanía" para, luego, desplegar la crítica a esta segunda noción. Y es que, a mi entender, la noción de "soberanía" 
daría cuenta de las dificultades en la asunción de responsabilidades jurídicas. Finalmente, a partir de lo anterior se extraerán conclusiones en la dimensión ambiental.

Para sentar las bases del análisis del concepto de "responsabilidad" se ha creído conveniente recurrir al pensamiento de Nietzsche. Creo que tal conveniencia se puede justificar en los siguientes motivos. En primer lugar, si bien es cierto que Nietzsche no escribió sobre temas medioambientales, sus reflexiones acerca de los orígenes ${ }^{1}$ de los valores morales, del Derecho, del Estado y de la idea de responsabilidad los analiza a partir, precisamente, de la dualidad cultura/naturaleza (o razón/instinto), dualidad que se intuye muy pertinente para analizar la problemática medioambiental. En segundo lugar, es considerado el pensador crítico por excelencia de la tradición del pensamiento occidental, también del modo tradicional de enfocar las relaciones entre cultura y naturaleza. A mi parecer, el pensamiento de Nietzsche contribuye a entender los problemas actuales que provienen de esa tradición. En tercer lugar, a pesar de la radicalidad de su crítica, su planteamiento se mueve dentro de los parámetros tradicionales, pues básicamente invierte el sentido de las relaciones entre cultura y naturaleza, pero manteniendo los mismos presupuestos que subyacen tras esa contraposición. En cambio, este trabajo apunta hacia la necesidad de redefinir la manera misma cómo se comprenden las relaciones entre los elementos de aquellos binomios. Así pues, Nietzsche no sólo resulta un buen referente para criticar el planteamiento tradicional, sino también un buen punto de partida para criticar la posición opuesta, pero inserta en esa misma tradición. Para llevar a término la crítica al planteamiento de Nietzsche, se recurrirá alternativamente a la obra de Agamben.

Sólo un último comentario introductorio. Nietzsche es un pensador que se presta a múltiples interpretaciones $^{2}$. Así, hay quienes defienden que de su pensamiento se puede extraer una teoría ética medioambiental ${ }^{3}$, y quienes consideran que no ${ }^{4}$. Aquí se parte del Nietzsche vitalista, como filósofo que sitúa la noción de "vida" en el centro de su pensamiento, a partir de la cual lanza sus invectivas

\footnotetext{
${ }^{1}$ Acerca del método genealógico en Nietzsche, ver FOUCAULT. M., Nietzsche, la genealogía, la historia, $7^{\mathrm{a}}$ ed., Valencia. Pre-Textos, 2014.

${ }^{2}$ Ver WOORDWARD, A. (ed.), Interpreting Nietzsche: Reception and Influence, London, etc. Continuum, 2011.

${ }^{3}$ Por ejemplo, STOREY, D.E., "Nietzsche and ecology revisited: the biological basis of value", Environmental ethics, v. 38, $\mathrm{n}^{\circ} 1,2016$, pp. 19-45; DRENTHEM, M., "Wildness as a critical border concept: Nietzsche and the debate on wilderness restoration", Environmental values, v. 14, n 3, 2005, pp. 317-337; DRENTHEM, M., "Nietzsche and the paradox of environmental ethics", New Nietzsche Studies, v. 5, no 1/2, 2002, p. 12-25; HALLMAN, M., "Nietzsche's Environmental Ethics", Environmental Ethics, v. 13, n' 2, 1991, pp. 99-125.

${ }^{4}$ ACAMPORA, R., "Using and Abusing Nietzsche for Environmental Ethics,” Environmental Ethics, v. 16, n 2, 1994, pp. 187-94.
} 
contra la cultura occidental, al tiempo que articula su teoría política. De esa lectura de Nietzsche son deudoras, y también críticas, las teorías biopolíticas, incluida la de Agamben y la que aquí se presenta.

\section{La noción de "responsabilidad" (verantwortlichkeit) en Nietzsche}

\subsection{Responsabilidad en el conflicto interno entre lo animal y lo humano}

En la Genealogía de la moral ${ }^{5}$, Nietzsche sostiene que el ser humano se distingue del resto de animales por ser un animal con memoria, "capaz de hacer promesas" (das versprechen darf) y de asumir responsabilidades. Esos rasgos distintivos guardarían relación entre sí. Sólo un animal capaz de hacer promesas puede asumir responsabilidades; a su vez, sólo un animal con memoria tiene capacidad para hacer promesas. La memoria sería la facultad que mediaría entre el acto en que se promete algo y el acto que da cumplimiento a la promesa. En lo que sigue, se recurrirá al término "recuerdo" para referirse a lo que Nietzsche denomina "memoria” (gedächtniss) ${ }^{6}$.

Que el ser humano se distinga del resto de animales por el hecho de poder recordar no significa que el ser humano no sea una especie animal; más bien, abriría un conflicto en el seno del ser humano entre su animalidad y aquel rasgo específicamente humano. Según cómo se articule ese conflicto, Nietzsche distingue dos posibles tipos de ser humano.

En primer lugar, estarían los "hombres" (menschen)7. Según Nietzsche, los hombres dispondrían de la facultad de recordar, si bien carecerían de la fuerza de voluntad suficiente como para mantener a cualquier precio la promesa que se hacen a sí mismos de permanecer fieles a sí mismos. Su impotencia para soportar el sufrimiento que terceras personas les infligirían en caso de negarse a cumplir con las promesas hechas a terceros con el propósito de mantenerse fieles a sí mismos les

\footnotetext{
${ }^{5}$ NIETZSCHE, F., La genealogía de la moral, Madrid. Alianza Ed., 1997, p. 75-77 (Segundo tratado, ap. 1 y 2).

${ }^{6}$ Con "tener memoria", Nietzsche quiere significar poder recordar, más exactamente, tener la capacidad de abstraerse del momento presente para recuperar un momento pasado en el que se habría formulado prospectivamente una promesa. Esta distinción es significativa, pues sería esa capacidad de recordar, y no el tener memoria, una de las características que distinguiría al ser humano del resto de animales. La distinción entre memoria y recuerdo resulta relevante, pues guarda relación con la distinción entre acción reflexiva y acción puramente instintiva. Muy sintéticamente, al no poder recordar, los animales serían incapaces de abstraerse de la realidad presente y de ensimismarse reflexivamente en su propia interioridad (es decir, de tener conciencia de sí mismo a través de sus recuerdos y de su proyección hacia el futuro), por lo que permanecerían atrapados en la (re)acción inmediata, instintiva (que puede que sea aprendida) a la que una determinada situación presente les impelería. El ser humano, en cambio, permanecería abierto al mundo gracias a su capacidad para recordar y proyectarse. Ver AGAMBEN, G., Lo abierto. El hombre y el animal, Valencia. Pre-Textos, 2005, p.55-73.
}

7 NIETZSCHE, F., Aurora, Madrid. Edaf, 1996, p. 149-150 (ap. 105). A pesar del lenguaje claramente machista, se mantiene la terminología nietzscheana para hacer referencia a este tipo. 
llevaría a la aceptación de la existencia de una deuda (schulden) para con el otro ${ }^{8}$, es decir, al reconocimiento de las promesas que han formulado a terceros como obligaciones que les vinculan y a la aceptación de la existencia de responsabilidades morales y/o jurídicas. Los hombres anteponen las obligaciones contraídas con los demás a las que tienen consigo mismos ${ }^{9}$. Aún de otra manera, aceptan vivir en sociedad al precio de ver limitada su libertad, de dejar de ser ellos mismos, con miras a evitar una serie de posibles severos castigos ${ }^{10}$. A cambio obtendrían tranquilidad y seguridad, pues no sólo evitarían sufrir daños al no causarlos, sino que recibirían la protección del grupo frente a los perjuicios que otros les pudieran ocasionar. En el caso de los hombres, el recuerdo mediaría entre un prometer a otro un (no) hacer, y la (in)acción que da cumplimiento a esa promesa. Ser responsable consiste en atender a lo que se prometió a un tercero en un momento pretérito ${ }^{11}$ : la (in)acción mira hacia el pasado como forma de dar cumplimiento a la obligación contraída cuando ésta deviene exigible. Que la acción debida coincida o no con su voluntad (con su "yo quiero") resulta secundario: ante todo, cumpliría para evitar el daño; la voluntad (el "yo quiero") que es satisfecha es la de un tercero.

En segundo lugar, estarían los "hombres-animales” (Mensch-thiere). Éstos no sólo dispondrían de la facultad de recordar, por lo que serían capaces de hacerse la promesa a sí mismos de mantenerse fieles a sí mismos, sino que además dispondrían de la fuerza de voluntad necesaria para mantenerla. Este tipo de seres humanos merecerían el adjetivo de "animales" porque, lejos de avergonzarse de sus instintos y de reprimirlos, actuarían movidos por ellos y con miras a su satisfacción. En este sentido, "actuar instintivamente" no significa lo habitual: significa ser egoísta, actuar y reaccionar conforme a los valores y las normas que uno mismo se da, no guiarse por las convenciones sociales. Aquí el recuerdo mediaría entre el acto de formación de su voluntad (un "yo quiero") y el acto de realización de esa voluntad. Se trata, pues, de un recuerdo abocado hacia la acción, hacia el futuro ${ }^{12}$. Aquí, la responsabilidad se evalúa en función del resultado alcanzado, de la obra creada ${ }^{13}$.

\footnotetext{
${ }^{8}$ NIETZSCHE, F., Genealogía..., op. cit., 1997, p. 81-83 (Segundo tratado, ap. 4). Sobre la finalidad de la justicia retributiva, ver NIETZSCHE, F., Humano, demasiado humano, Madrid. Edaf, 1996, p. 103 (pár. 105).

${ }^{9}$ NIETZSCHE, F. El crepúsculo de los ídolos, en "Friedrich Nietzsche. Obras inmortales", vol. III, Madrid. Edicomunicación, 2003, p. 1355 (ap. 39).

${ }^{10}$ NIETZSCHE, F., Genealogía..., op. cit., 1997, p. 81 (Segundo tratado, ap. 3).

${ }^{11}$ NEHAMAS, A., "Nietzsche, intention, action”, European Journal of Philosophy, no 26, 2018, p. 685-701.

12 NIETZSCHE, Genealogía..., op. cit., 1997, p. $76-77$ (Segundo tratado, ap. 1).

${ }^{13}$ NEHAMAS, “Nietzsche,...”, op. cit, 2018.
} 


\subsection{Responsabilidad en la dimensión socio-política del conflicto entre lo animal y lo humano. El individuo soberano como individuo responsable}

La disputa interna al ser humano entre razón e instinto tiene su correlato en la dimensión comunitaria.

Que el hombre-animal se guíe conforme a las normas que se da a sí mismo implica que sólo obedece a sí mismo, no a los demás: es autónomo y, por lo tanto, no es moral ${ }^{14}$. Desde el punto de vista de la teoría de la responsabilidad, "individuo autónomo" se puede definir como aquel que, primordialmente, responde sólo ante sí mismo ${ }^{15}$, que se exige cumplir con la promesa que se hace a sí mismo de permanecer fiel a sí mismo (a su destino), pero no necesariamente con las que hace a quienes no son capaces de mantener para sí semejante promesa ${ }^{16}$. Aún de otra manera, el hombre-animal sería el hombre fiel a sus instintos, sean cuales sean las consecuencias que se deriven, incluso aunque esa consecuencia sea la propia muerte; es más, cuanto mayor el peligro a afrontar, mayor la libertad que se alcanza $^{17}$ : el ser humano libre vive peligrosamente. La amenaza de sufrir daños severos o, incluso, de morir sería real, pues quien se considera irresponsable respecto a las promesas hechas a terceros tiene que contar con la posibilidad de que esos terceros que ven defraudadas sus expectativas reaccionen violentamente.

\footnotetext{
${ }^{14}$ NIETZSCHE, Genealogía..., op. cit., 1997, p. 78 (Segundo tratado, ap. 2).

15 NIETZSCHE, F., "De Schopenhauer como educador. Tercera consideración intempestiva”, en Consideraciones intempestivas, 187376, Buenos Aires. Alianza, 2002, p. 97ss.

${ }^{16}$ Hay posiciones encontradas en torno al significado y la importancia de la noción de "individuo soberano" en la obra de Nietzsche. Mientras que algunos la consideran central (ver GEMES, K.; JANAWAY, C., "Nietzsche on free will, autonomy and the sovereign individual", en K. Gemes; S. May (eds.), Nietzsche on freedom and autonomy, Oxford. Oxford University Press, 2009, p. 33-50); OWEN, D., "Autonomy, self-respect, and self-love: Nietzsche on ethical agency", en K. Gemes; S. May (eds.), Nietzsche on freedom and autonomy, Oxford. Oxford University Press, 2009, p. 197-222), otros entienden que no sólo resulta un concepto marginal, sino que, cuando aparece, es objeto de críticas (ver HATAB, L. J., A Nietzschean Defense of Democracy: An experiment in Postmodern Politics, Chicago. Open Court, 1995, p. 37-38; ACAMPORA, C. D., "On sovereignty and overhumanity. Why it matters how we read Nietzsche's Genealogy 11:2", en C. D. Acampora (ed.), Critical Essays on the Classics: Nietzsche's On the Genealogy of Morals, Lanham. Md. Rowman \& Littlefield Publishers, 2006, p. 147-161). Los primeros se fijan primero en la dimensión individual de la responsabilidad, para luego fundamentar la responsabilidad jurídica, esto es, frente a terceros; los segundos resaltan de buen comienzo el componente agónico, inevitablemente relacional, del pensamiento nietzscheano. La posición aquí mantenida se aproxima más a la primera posición, pero con una diferencia crucial: Gemes, Janaway y Owen consideran que es "soberano" aquel individuo que, como que cumple con las promesas concretas que se ha hecho a sí mismo en el pasado, en consecuencia, cumple con las que ha hecho a los demás al entenderlas también como un producto de su voluntad individual, lo cual conlleva asumir responsabilidades ante otros; personalmente me parece que la noción "soberanía" en Nietzsche se aproxima más a la posteriormente desarrollada por SCHMITT, C., El concepto de lo político, Madrid. Alianza Ed., 1998, y AGAMBEN, G., Estado de excepción. Homo sacer II, 1, Valencia. Pre-Textos, 2004, es decir, como aquel individuo que decide sobre el estado de excepción, o, en otras palabras, que decide sobre la suspensión de su sometimiento a cualquier norma abstracta (es decir, a cualquier promesa formulada en el pasado) si considera que concurre un estado de necesidad (si su "destino", lo que él es en el porvenir, está en jaque). Según mi lectura de Nietzsche, "ser responsable" no significa cumplir con la norma (o promesa) que uno se ha dado a sí mismo en el pasado, sino permanecer fiel a uno mismo, a su ser, a su destino.
}

${ }^{17}$ Sobre el concepto de libertad, ver NIETZSCHE, Crepúsculo..., op. cit., 2003, p. 1353-1355 (ap. 38). 
Nietzsche califica tal individuo autónomo de "individuo soberano" (souveraine individuum): su poder para no dejarse gobernar por otros y gobernarse a sí mismo le convierte en legislador, es decir, en creador de nuevos valores, de nuevos mundos, de nuevas verdades, de nuevas morales ${ }^{18}$. Soberano es sinónimo de agente creador. En apariencia, lo que se tiene por verdadero o falso se presenta bajo la dicotomía entre lo posible y lo imposible. Pero la verdad se sostiene siempre sobre un determinado esquema de valores ${ }^{19}$, de manera que aquella dicotomía opera como velo de la verdadera dicotomía, aquella entre lo que se considera que debe o no debe ser. Acceder a la verdad, la que subyace tras la superficie, requiere percatarse del engaño que supone tal realidad y el modo cómo se presenta ${ }^{20}$. En el fondo, la realidad tal y como aparece, lo que “es", consiste en una construcción que viene definida y determinada por quienes consiguen imponer su visión del mundo, su voluntad, su idea de lo que "debe ser" a otras voluntades ${ }^{21}$.

El interés fundamental de Nietzsche no parece radicar en el ámbito de la política, sino en la irrupción de individuos creadores de cultura personificados en las figuras del filósofo ${ }^{22}$ y del $\operatorname{artista~}^{23}$, por lo que podría parecer que el individuo soberano carece de relevancia política. En esa línea, Gentili ${ }^{24}$ concluye que el aristocratismo nietzscheano sería fundamentalmente espiritual, no social o político. Con todo, tal posición resuena indefectiblemente en estos otros ámbitos, cuando menos por las siguientes dos razones: en primer lugar, si es deseable la irrupción de una casta de individuos artistas, entonces urge preocuparse por las condiciones sociales y políticas más adecuadas para su generación. En segundo lugar, en la medida en que el individuo soberano crea, a través de su obra, nuevos valores y un nuevo mundo, pone inevitablemente también en cuestión la verdad y la moral vigentes y, por ende,

\footnotetext{
${ }^{18}$ NIETZSCHE, F., Más allá del bien y del mal, Madrid. Alianza Ed.,1997, p. 211-212 (p. 165-167).

${ }^{19}$ FINK, E., La filosofía de Nietzsche, Madrid. Alianza Ed., 1976.

${ }^{20}$ NIETZSCHE, F., "Sobre verdad y mentira en sentido extramoral", en F. Nietzsche, H. Vaihinger, Sobre verdad y mentira. $5^{\mathrm{a}}$ ed., Madrid. Tecnos, 2007, p. 15-38. Sobre este tema ver también el estudio realizado por VAIHINGER ("La voluntad de ilusión en Nietzsche") recogido en este mismo libro, y QUESADA, J., Un pensamiento intempestivo. Ontología, estética y política en F. Nietzsche, Barcelona. Anthropos, 1988, p. 167-177.

${ }^{21}$ NIETZSCHE, Genealogía ..., op. cit., 1997, p. 190-193 (Tercer tratado, ap. 24); NIETZSCHE, Más allá..., op. cit., 1997, p. $62-66$ (cap. II, ap. 34 y 35). Sobre el espejismo de las identidades individuales (de los "yo") y los orígenes de su conformación que revelan la previa creación e imposición de determinados valores, ver QUESADA, J., "Nietzsche: risa, genealogía, carnaval. El teatro del <yo>", en VVAA, Actualidad de Nietzsche: hacia nuevos horizontes. Michel Foucault: arqueología del poder y de las resistencias, Ciclos de conferencias sobre Michel Foucault i Nietzsche. La Coruña, abril 93-abril 94, La Coruña. Fundación Paideia, 1994, p. 51-66.

22 DELEUZE, G., Nietzsche y la filosofia, 4a ed., Barcelona. Anagrama, [1967] 1994.

${ }^{23}$ RIDLEY, A., "Nietzsche, On art and freedom”, European Journal of Philosophy, 2007, v. 15, n 2, p. $204-224$.

${ }^{24}$ GENTILI, C., “Nietzsche: ¿político o apolítico?”, Estudios Nietzsche, Madrid. Trotta, no 12, 2012, p. 105-116.
} 
los poderes establecidos, de forma que aquella adquiere, ni que sea como efecto colateral, trascendencia política. En su quehacer creador, el filósofo y el artista hacen política.

Pero la relación entre creación cultural y política también corre en el sentido inverso. Así, Nietzsche concibe también al político como un agente creador de valores y realidades, como un artista, sólo que, en su caso, como un artista de la violencia, violencia cuyo ejercicio quedaría justificado por el valor de su creación y el fomento del genio artístico y la cultura ${ }^{25}$. En esto último consistiría, para Nietzsche, ser responsable políticamente.

De manera crucial, el dominio que tiene el político-artista sobre sí mismo ${ }^{26}$ derivaría necesariamente "en un dominio de las circunstancias, de la naturaleza y de todas las criaturas menos fiables, más cortas de voluntad"27. Únicamente quien sólo atiende a las promesas que se hace a sí mismo, porque es capaz de cumplirlas, está en posición de exigir, a quienes no son capaces de asumir responsabilidades para consigo mismos, que cumplan con las promesas que éstos le hacen. Expresado aún de otra manera, el individuo soberano es capaz de generar un nuevo marco de responsabilidades jurídicas para quienes no son capaces de obedecerse a sí mismos precisamente porque, al mismo tiempo, él mismo es irresponsable jurídicamente ante éstos.

\subsection{El locus del individuo soberano: entre la polis y la physis}

Nietzsche se remite a Hobbes para situar los orígenes del Estado (y, por tanto, del Derecho) en la violencia y la guerra de todos contra todos. Con todo, la valoración que Nietzsche hace de la guerra como fundamento del Estado en el conjunto de su obra resulta ambivalente, si es que no contradictoria ${ }^{28}$. En "La lucha de Homero"29, Nietzsche parece contemplar dos posibles modos de relacionarse los hombres-animal entre sí.

\footnotetext{
${ }^{25}$ NIETZSCHE, F., “El estado griego”, Ensayos sobre los griegos, Buenos Aires. Ediciones Godot, 2013, p. 7-25.

${ }^{26}$ Sobre la independencia como condición para la autonomía personal y la capacidad de mando, ver NIETZSCHE, Más allá..., op. cit., 1997, p. $70-71$ (cap. II, ap. 41).

${ }^{27}$ NIETZSCHE, Genealogía ..., op. cit., 1997, p. $77-79$ (Segundo tratado, ap. 2). Ver también NIETZSCHE, Crepúsculo..., p. $1367-1368$ ("Lo que debo a los antiguos", ap. 2).

${ }^{28}$ Sobre los pros y contras de la guerra, NIETZSCHE, Humano..., op. cit., 1998, p. 250 (VIII, ap. 444).

29 NIETZSCHE, F., "La lucha de Homero", 1871-1872 (disponible en: http://190.186.233.212/filebiblioteca/Ciencias\%20Sociales/Friedrich\%20Nietzsche\%20-\%20La\%20lucha\%20de\%20Homero.pdf, última consulta mayo de 2020).
} 
Cabría, primeramente, como habría sucedido en la Grecia antigua homérica, que la lucha entre individuos soberanos se canalice de manera agonal: estos espíritus libres, creativos, competirían entre sí, cada uno en su ámbito, por crear una obra que prevalezca sobre sus rivales en una dinámica productiva que se retroalimentaría. Quienes así competirían se reconocerían entre sí como iguales, es decir, conforme a reglas, pero despreciando a quienes fueran incapaces de entrar en la competición, esto es, los "hombres". En la polis griega homérica, se habría conseguido compatibilizar la perenne rivalidad entre esos individuos soberanos con la vida en sociedad. Gracias a aquel modo de lucha se habrían creado formas de comprender, justificar y hacer soportable la existencia (esto es, el mundo apolíneo, el mundo ordenado por el principio de individuación) frente a las fuerzas disolutivas y reintegradoras de la individualidad en la naturaleza (es decir, lo dionisíaco, o la physis ${ }^{30}$ ); aunque no hay que olvidarse de toda la carga idealizante que se atribuye a la vuelta a los orígenes.

En segundo lugar, puede darse una situación en que uno de esos individuos soberanos sea suficientemente poderoso como para lograr la eliminación de sus competidores. Para los griegos antiguos, tal situación resultaría indeseable, pues pondría en peligro la competición misma. En el terreno de la política, ese acaparamiento monopólico de la creación jurídica y del uso de la violencia autolegitimada resultaría particularmente odiosa, pues daría pábulo a la guerra, en la cual se desatarían las peores formas de crueldad humana. Así idealizada, la Grecia homérica es utilizada como crítica para la noción al uso de "soberano", personificada en la figura de Alejandro Magno ${ }^{31}$.

En cambio, en "El Estado griego"32 justifica la guerra como principio fundador del Estado, así como la esclavitud en tanto que "males necesarios" que promueven la producción artística, alabando la figura del filósofo-rey y la división social en castas de la teoría política platónica (y ello sin menoscabo

\footnotetext{
${ }^{30}$ Ver NIETZSCHE, F., El origen de la tragedia, $8^{\mathrm{a}}$ ed., Madrid. Espasa-Calpe, 2000; o también NIETZSCHE, F., La voluntad de poder, Madrid. Edaf, 2000, p. 565-568 (ap. 848). Para un interesante exposición y reflexión en torno a las relaciones entre lo apolíneo y lo dionisíaco en la Grecia antigua en el pensamiento de Nietzsche, ver SANZ, R., "La política nietzscheana y la imagen de Grecia", en R. Sanz (coord.), Nietzsche: modernidad y política, Madrid. Dykinson, 2013, p. 105-149). Sobre el trasfondo caótico del mundo, ver también, NIETZSCHE, F., La ciencia jovial, Madrid. Gredos, 2010, p. 426 (ap. 109).

${ }^{31}$ NIETZSCHE, “La lucha de homero", op. cit., 1871-1872, p. 1-2 y 7.

32 NIETZSCHE, “El Estado griego”, op. cit., 2013.
} 
de que, junto a Sócrates, sea diana de continuas críticas a lo largo de su obra), así como la figura del príncipe renacentista ${ }^{33}$.

Sea como fuere, en la "polis postalejandrina" (léase también "época moderna"), la domesticación de la masa respondería a la voluntad de acumulación de poder por parte del gobernante, objetivo que habría devenido el fin mismo de la acción política contemporánea. Desvinculada la comprensión social de la realidad como producto del despliegue de las fuerzas dionisíacas (destructivas pero creativas al mismo tiempo ${ }^{34}$ ), tal domesticación habría resultado en el ahogamiento de la creatividad humana, fenómeno histórico que no es sino otra forma de referirse al proceso de racionalización. La polis postalejandrina se configura, pues, como una sociedad de hombres que olvidan el hecho de estar gobernados por un individuo soberano.

A partir de lo anterior, y en términos de teoría de la responsabilidad, la polis se puede definir como aquel ámbito en que las personas se hacen promesas entre sí que aceptan como vinculantes, dando lugar a obligaciones morales y/o jurídicas y a la asunción de responsabilidades frente a terceros. En la polis homérica, los individuos soberanos respetan las promesas que se formulan mutuamente ${ }^{35}$, pero no aquellas que formulan a los hombres inferiores. En la polis postalejandrina, la igualación entre hombres derivaría en el sometimiento de todos a la ley. Physis (o "estado de naturaleza") haría referencia al reverso que requeriría la afirmación de la vida en sociedad, es decir, a un estado de vida pre-social en el cual los individuos se guiarían por sus instintos y, por tanto, se considerarían irresponsables en principio ante los demás (en la polis homérica, irresponsables ante quienes no son sus iguales). Ajenos a las convenciones sociales, tales individuos se encontrarían en disposición de ejercer una violencia ilimitada sobre los demás, hallándose igualmente en situación de poder sufrirla por parte de los demás. Pero esa misma violencia resultaría en la construcción de un orden político-social. La

\footnotetext{
${ }^{33}$ El desencuentro entre las dos posturas expuestas en la nota 15 alcanza también a la teoría de los sistemas políticos. Así, por ejemplo, HATAB, L., "Prospects for a democratic agon. Why we can still be Nietzscheans", Journal of Nietzsche Studies, $\mathrm{n}^{\circ}$ 24, 2002, pp. 132147, enfatiza la defensa nietzscheana de la lucha competitiva, mientras que OWEN, “Autonomy...”, op. cit., 2009, p. 217, subraya los elogios de Nietzsche a pensadores como Tucídides y Maquiavelo. CONWAY, D., "The birth of the State", en H. W. Siemens; V. Roodt (eds.), Nietzsche, power and politics: rethinking Nietzsche's legacy for political thought, Berlin; New York. Walter de Gruyter, 2008, p. 37-38, tal vez da la clave para superar esa aparente contradicción. Según este último, para Nietzsche, la política es sólo un medio para la consecución de un bien superior, el de la superación del ser humano a través del arte: todo régimen que satisfaga dicha condición estaría legitimado.

${ }^{34}$ Para una crítica a la persona y pensamiento de Platón, ver el ya citado apartado NIETZSCHE, Crepúsculo..., p. 1367-1368 (“Lo que debo a los antiguos", ap. 2).

${ }^{35}$ NIETZSCHE, Genealogía..., op. cit., 1997, p. $78-79$ (Segundo tratado, ap. 2).
} 
physis hace, pues, referencia a un espacio al mismo tiempo disolutivo (extraño a la comunidad política) y constitutivo (interno a la comunidad política) del orden político-social.

El locus del hombre está bien delimitado: la polis postalejandrina. El hombre, incapaz ya de soportar los peligros y el sufrimiento derivados del estado de naturaleza, encuentra en los espacios humanizados un lugar donde obtener protección y vivir con seguridad. En cambio, el individuo soberano se ubicaría en un locus muy particular de indefinición entre aquellas dos topografías, la de la polis y la physis. Por un lado, es creador de ley y de orden. Pero él mismo, en tanto que responsable sólo ante sí mismo y no ante los demás, no queda sujeto a esa normatividad que constituye la vida en sociedad; al situarse fuera de ésta, deviene fuente de desorden.

\section{Individuo soberano y homo sacer}

Ese ámbito tan particular de indefinición entre los espacios humanizados y lo que queda fuera de ellos en que se halla el legislador (o soberano) se corresponde con el ámbito de lo sagrado. Lo sagrado, a su vez, versa sobre el derecho a disponer de la vida y de la muerte. La muerte de dios anunciada por Nietzsche tiene un responsable: dios es matado por quien no obedece a otra autoridad externa a sí mismo; y, como sólo se obedece a sí mismo, ese individuo deviene un dios ${ }^{36}$, es decir, alguien que puede matar con impunidad ${ }^{37}$, pero que es susceptible de ser matado también impunemente.

El pensamiento de Agamben permite profundizar algo más en las relaciones entre lo sacro y esa peculiar posición del individuo soberano. Agamben vincula la noción de "soberano" con la del homo sacer, que sería aquella vida humana situada en un espacio de irreductible indiferencia entre la vida fuera de la sociedad (en un estado de naturaleza o physis) y la vida en sociedad (polis). De una manera más técnica y precisa, Agamben define "homo sacer" como aquella vida humana a la que cualquiera puede dar muerte impunemente, pero que, simultáneamente, no puede ser sacrificada de acuerdo con los rituales establecidos. Que se le pueda dar muerte con impunidad supone la suspensión de la

\footnotetext{
${ }^{36}$ NIETZSCHE, La ciencia jovial, op. cit., 2010, p. 439-441 (ap. 125).

${ }^{37}$ Esta idea viene reflejada en la siguiente cita en torno al origen y fundamento del Estado: "Y así como en realidad el concepto del derecho griego se ha derivado del asesinato y del pecado de homicidio, la más noble cultura toma su guirnalda de triunfo del altar de este pecado.” (NIETZSCHE, "La lucha de Homero": op. cit., 1871-1872, p. 2).
} 
aplicación de la ley convencional. Así pues, quien acaba con esa vida no comete homicidio, quedando en principio eximido de cualquier responsabilidad precisamente por el carácter sagrado de la víctima, es decir, porque esa vida está situada fuera del Derecho convencional. Pero el hecho de que la comunidad permita darle muerte con impunidad supone una forma de inclusión en ella, si bien excluyente al mismo tiempo. Por otro lado, esa vida también queda fuera del ámbito del Derecho divino, pues no puede ser sacrificada ritualmente, de manera que quien acaba con ella tampoco comete sacrilegio, permaneciendo exento, también en este campo, de toda responsabilidad. Esa vida que es exceptuada de todo Derecho, despojada de cualquier protección, sobre la cual el poder soberano puede ejercer violencia con impunidad, la denomina "nuda vida" ${ }^{38}$. Es una vida cuya muerte no genera responsabilidades si se mira desde la perspectiva de que se mata a quien, por derecho, se considera que no existe; o expresado de otra manera, a quien se considera que ya no existe porque no debería existir. En breve, "homo sacer" ("nuda vida") es aquella vida humana sobre la cual se puede ejercer violencia sin que la víctima tenga derecho a exigir responsabilidades jurídicas; "soberano" es quien puede ejercer violencia sobre esa vida sin que se le puedan exigir responsabilidades jurídicas ${ }^{39}$.

El "bandido" o "proscrito" sería una de las categorías que, según Agamben, se hallaría en esa especial relación respecto al poder soberano. "Bandido" sería aquel que atenta contra la paz de la comunidad y, como consecuencia, aquel que tampoco tiene paz, pues la comunidad se declara en estado de guerra contra él ${ }^{40}$. Atentaría contra la paz de la comunidad porque, al tratarse de un individuo autónomo, no sólo no aceptaría someterse a las leyes de la comunidad, sino que además legislaría sobre los demás al legislar sobre sí mismo. No se trata, pues, simplemente de un individuo que no atiende a la ley, sino de un individuo que, al poner en cuestión el poder soberano y amenazar con ello la continuidad de la comunidad política, es expulsado de ésta, dejando de gozar de la protección y la seguridad de la vida en sociedad. De esa forma, el poder soberano pasaría a mantener con el bandido el tipo de relaciones propias del estado de naturaleza, es decir, de aquel estado en el que se puede matar al otro con impunidad sin que pueda ser sacrificado, en el que cada cual es para el otro homo sacer, nuda

\footnotetext{
${ }^{38}$ AGAMBEN, G., Homo sacer. El poder soberano y la nuda vida, Valencia. Pre-Textos, 1998, p. 106ss.

39 "Soberana es la esfera en que se puede matar sin cometer homicidio y sin celebrar un sacrificio; y sagrada, es decir, expuesta a que se le dé muerte, pero insacrificable, es la vida que ha quedado prendida en esa esfera." (AGAMBEN, Homo sacer..., op. cit., 1998, p. 109).

${ }^{40}$ AGAMBEN, Homo sacer..., op. cit., 1998, p. 135-143. La figura agambiana del "bandido" encuentra correspondencia en Nietzsche en la figura del "delicuente" o "proscrito", si bien parece acotar su existencia a las comunidades más primitivas. Ver NIETZSCHE, Genealogía ..., op. cit., 1997, p. $92-95$ (Segundo tratado, ap. 9 y 10).
} 
vida. Con todo, que el tipo de relaciones sean las propias del estado de naturaleza no significa que el bandido quede completamente excluido de la comunidad, pues al mismo tiempo es incluido dentro de ella de dos modos interconectados entre sí. Primeramente, en la medida en que sería responsable ante sí mismo y, por ello, le sería lícito exigir responsabilidades a los demás, deviene potencialmente un poder soberano para esa misma comunidad que se siente amenazada. En segundo lugar, en tanto que competidor del poder soberano, éste no tiene la opción de eludir el conflicto. Ese conflicto ineludible con el bandido supone una forma de inclusión dentro de la comunidad, sólo que como aquel que puede ser matado con impunidad por cualquiera. El poder soberano se caracteriza por su tendencia a la omnicomprensividad: nada queda potencialmente fuera de la polis, ni siquiera lo que es excluido de ella.

Así pues, "bandido" (o "proscrito") es aquel que, desde el punto de vista del poder soberano, y al igual que éste, reúne los rasgos que caracterizan al individuo soberano. Pero también es cierto lo opuesto. Por el tipo de relación que mantiene con el bandido, el poder soberano se configura como homo sacer, esto es, como alguien que puede ser matado con impunidad por parte de ese a quien considera bandido, pero que puede devenir poder soberano. El soberano y el bandido son ambos individuos autónomos, situados en un espacio de indiferenciación entre la physis y la polis; de ahí el estado, cuando menos latente, de guerra entre ellos.

Esa ambigüedad entre el soberano y el bandido también es recogida por Kelsen cuando recurre a la "banda de ladrones" para explicar los orígenes y la naturaleza del Estado y del Derecho. De acuerdo con este autor, la única diferencia entre una banda de ladrones y un Estado (una organización que se arroga poderes soberanos) radica en que las normas creadas por el Estado disponen de una eficacia duradera ${ }^{41}$. "Individuo soberano" sería aquel que dispone del poder de coacción suficiente como para que prevalezca la definición que hace de sí mismo como constituyente de un orden y la que hace de sus contendientes como bandidos que amenazan el orden constituido.

Volviendo a Agamben, el acto constituyente de la comunidad guardaría relación, no con el momento en que la comunidad se dota formalmente de una norma constitucional, sino, bien al contrario, cuando el orden constitucional queda suspendido, es decir, cuando los límites que el Derecho

${ }^{41}$ KELSEN, H., Teoría pura del Derecho, 16ª ed., México. Ed. Porrúa, 2009, p. 57-63. 
impone al Estado son suprimidos. Tal suspensión supone una vuelta a la relación fundamental entre poder soberano y homo sacer (o "nuda vida"). El estado de naturaleza sería el postulado necesario para dar cuenta de aquella situación de excepción ${ }^{42}$. Así pues, la figuración de un enemigo que amenaza la continuidad de la comunidad política requiere de la postulación de un estado de naturaleza, en tanto en cuanto lo amenazante surgiría de ese espacio de indiferenciación entre el estado de naturaleza y el orden comunitario.

Tal amenaza contra la continuidad del orden político sólo puede provenir del hombre-animal. El individuo temible, soberano, es aquel que se mueve en ese espacio de indistinción entre la polis y la physi $^{43}$. Su ámbito propio es el del estado de excepción. En ese ámbito, la distinción entre lo humano y lo animal se disuelve ${ }^{44}$. Ni hombre, ni animal, ni dentro ni fuera de la ciudad o la naturaleza, el hombre-animal se corresponde con el hombre sagrado ${ }^{45}$.

De todo lo anterior, se pueden extraer dos conclusiones relevantes. Primera. Precisamente porque el hombre-animal sería responsable políticamente (en el sentido de que su acción es potencialmente destructiva y constitutiva de un orden político comunitario), se le despoja de todo derecho y se le reduce a nuda vida, quedando ubicado en una esfera de indeterminación respecto a las posibles responsabilidades jurídicas por los daños que alguien le pudiera causar. Segunda. En virtud de aquella doble faceta del hombre-animal (soberano y bandido), así también son dos los posibles modos en que se le concibe y se le trata. Como soberano (divino), al hombre-animal se le debe temer, venerar y obedecer; como proscrito (demoníaco), se le teme, repudia y combate. Ambos tratamientos no sólo no se excluyen, sino que tienden a converger: precisamente porque se le venera, se le tiene que matar.

\footnotetext{
42 AGAMBEN, Homo sacer..., op. cit., 1998, p. 137-138.

${ }^{43}$ Sobre la conexión entre individuo soberano, la amenaza del uso de la violencia y el origen del Estado, ver NIETZSCHE, Humano..., op. cit., 1996, p. 97-98 (ap. 99).

${ }^{44}$ A este respecto, Agamben señala la figura monstruosa del "hombre-lobo" como paradigma del imaginario de ese hombre-animal. Sobre la figura del hombre-lobo en las tradiciones europea. Ver LLINARES, M., "Lobishome. La metamorfosis en lobo en las tradiciones europea y gallega", Memoria y civilización, $\mathrm{n}^{\circ}$ 17, 2004, p. 131-148). En la Grecia antigua, sobresale el mito de Licaón: PLATÓN, Diálogos IV. República, Madrid. Gredos, 2007, p. 418-419 (VIII, 565d-566b); LOZANO, F., "Los devoradores de hombres: el culto a Zeus Liceo y la licantropía en Arcadia", en Ferrer, E.; Marzuela, J.; Escacena, J. L. (coords.), De dioses y bestias: Animales y religión en el Mundo Antiguo, Sevilla. Universidad de Sevilla, 2008, p. 83-96). En la Roma antigua, sobresale el mito de Rómulo y Remo. En torno a este mito y las lupercalia como fiestas vinculadas a la fundación de la ciudad, ver CASCÓN, A. "Otra vez sobre Rómulo y Remo: Ciro y la leyenda del fundador", Myrtia, no 31, 2016, p. 58-64; RYKWERT, J., La idea de ciudad, Salamanca. Sígueme, 2002, p. 113-117; WISEMAN, P., "The God of the Lupercal", The Journal of Roman Studies, v. 85, 1995, p. 1-22). Ya en la modernidad, HOBBES, T., De cive, Madrid. Alianza ed., 2000, p. 33-34 y 43-45; y HOBBES, T., Leviathan, $2^{\text {a }}$ ed., Cambridge. Cambridge University Press, 1996, p. 86-90.

${ }^{45}$ AGAMBEN, Homo sacer..., op. cit., 1998, p. 136-137.
} 
He aquí otra manera más de referirse al "proceso de secularización” o "racionalización” del mundo mediante la dominación de la naturaleza, el cual, inevitablemente, conlleva la del propio ser humano. La contrapartida de ese "homicidio" (que quedaría fuera del ámbito de las responsabilidades jurídicas) es el nihilismo: en un mundo aparentemente seguro y ordenado por completo, sin nadie a quien venerar y/o repudiar, la existencia parece vaciarse de sentido para pasar a tenerlo el anuncio del fin de la historia.

\section{Responsabilidad ambiental. EI ambiente salvaje como amenaza}

En la medida en que el hombre-animal (el individuo soberano) se guía por sus instintos y permanece fiel a sí mismo, el hábitat considerado propio del hombre-animal por parte de los hombres es fuera de la vida en sociedad. Visto desde la perspectiva de quien habita en espacios humanizados o civilizados, el ambiente salvaje se configura como aquel territorio no sujeto al control humano, suponiendo, por ello mismo, una amenaza para aquellos territorios organizados conforme a convenciones sociales ${ }^{46}$.

Creo que sobre esta idea es posible ofrecer una definición operativa de "salvaje". "Salvaje" sería toda forma de vida (humana o no humana), territorio o fenómeno natural temible, que escaparía a la capacidad de control humano, a los cuales se atribuye un poder disruptivo y, por consiguiente, constituyente de la comunidad política. "Salvaje" es aquella existencia o acontecimiento que queda localizado en un espacio de indiferenciación entre la physis y la polis: en tanto que concebida como causa de orden y de caos para la comunidad, es incluida en ella de manera excluyente ${ }^{47}$.

Si, históricamente, han sido animalizados aquellos seres humanos que no se someten al orden comunitario (con la figura del hombre-lobo como paradigma), en la época pre-moderna fueron antropomorfizados aquellos animales, territorios o fenómenos naturales respecto a los cuales el ser

\footnotetext{
${ }^{46}$ Esta sería la idea rectora para interpretar el "Prólogo" de Así habló Zaratustra (NIETZSCHE, F., Así habló Zaratustra, 3 a ed., Alianza Ed., 2013, p. 41-62), texto donde Nietzsche expone las relaciones entre individuo soberano y sacralidad.

${ }^{47}$ SCHILLER, F., La educación estética del hombre, Buenos Aires; etc, Espasa-Calpe, [1795] 1943, distingue entre "salvaje” y "bárbaro" para referirse bien al ser humano que vive en estado de naturaleza sometido a sus emociones e instintos (salvaje), bien a aquel ser humano que, insensible, se impone despóticamente a otros seres humanos y los somete (bárbaro). Aquí se prefiere el concepto de "salvaje" para referirse al individuo (autónomo) que es situado fuera de la vida en sociedad. Ninguno de aquellos dos términos en su sentido tradicional logra recoger la doble faceta del individuo soberano, o, si se prefiere, el lugar ambivalente en que éste se localizaría. Respecto al concepto de "bárbaro" en particular, éste deja fuera animales, territorios o fenómenos naturales. Con los problemas que pueda suscitar, creo que el concepto de "salvaje" admite mejor la ambivalencia y la mayor extensión que se pretende significar aquí con su uso.
} 
humano ha tenido conciencia de que escapaban a su capacidad de control ${ }^{48}$. En la medida en que el ser humano disponía de una capacidad limitada para dominar y transformar el entorno en el que habitaba, o mejor, porque entendía que la realidad física cambiaba caprichosa y arbitrariamente, por causas que no alcanzaba a comprender, prever y controlar, esa naturaleza se le presentaba como inmutable, como realidades metafísicas no susceptibles de ser dominadas ${ }^{49}$. La realidad circundante se explicaba bien en términos de sustancias (esencias), bien mediante la adivinación, bien mediante la subjetivación y sacralización de las fuerzas terrenales como forma de reconocimiento de su ingobernabilidad, pero al mismo tiempo como modo de tratar de influir sobre ellas en la medida en que su consideración como sujetos (dioses) abría la posibilidad de comunicación y negociación con ellos ${ }^{50}$. En breve, se les atribuía voluntad propia y autonomía; esto es, se les consideraba como individuos autónomos.

A la hora de entender las relaciones entre el ser humano y el ambiente, la división realmente significativa sería también la misma que se traza en las relaciones entre seres humanos, a saber: aquella entre lo domesticado y lo salvaje. Así pues, y de manera similar al homo sacer, el trato como proscritos (demonización) o soberanos (divinización) también alcanza a aquellos animales salvajes, territorios o fenómenos naturales creídos potencialmente transgresores de elementos constitutivos de la comunidad, sólo que la terminología varía: en este caso la dualidad se mueve entre lo monstruoso y lo divino ${ }^{51}$. La physis se comprende como el territorio de los dioses y los monstruos y, por ello mismo, como un espacio que debería ser humanizado.

Si la pareja proscrito/soberano que se desplegaría en las relaciones entre personas es equiparable a la pareja monstruo/divinidad en las relaciones entre el ser humano y el ambiente,

48 NIETZSCHE, F., Humano..., op. cit., 1996, p.184 (ap. 246). La difuminación de la frontera entre lo humano y lo animal (y, por extensión, lo ambiental) encuentra su mejor expresión en el teriomorfismo. Sobre el sentido de las metamorfosis y el teriomorfismo, ver SMITH, M. S., Where the Gods are: spatial dimensions of anthropomorphism in the biblical world, New Haven; London. Yale University Press, 2016, p. 47-57; MORENO, M., "La naturaleza alterada. Imágenes de la metamorfosis animal en la antigua Grecia", en M. Jufresa; M. Reig (eds.), Ta Zôia. L'espai a Grècia II: els animals i l'espai, Tarragona. SCEC-ICAC, 2011, p. 105-120. BURCKHARDT, J., “Anexo. La metamorfosis”, Historia de la cultura griega, Madrid. RBA, v. I, 2005, p. 691-702.

${ }^{49}$ Van INWAGEN, P.; SULLIVAN, M., "Metaphysics", en Edward N. Zalta (ed.), The Stanford Encyclopedia of Philosophy, primavera 2018. <https://plato.stanford.edu/archives/spr2018/entries/metaphysics/> (última consulta: julio 2019).

${ }^{50}$ BUCKHARDT, J., “La indagación del porvenir”, en Jacob Burckhardt, Historia de la cultura griega, v. I, Madrid. RBA, 2005, p. 559ss; WHITROW, G. J., El tiempo en la historia. Barcelona. Crítica, 1990, p. 37-41. HORKHEIMER, M.; ADORNO, T., Dialéctica de la ilustración, $2^{\text {a }}$ ed., Madrid. Trotta, [1969] 1997, p. 59-128, exploran las conexiones del proyecto ilustrado moderno de dominación de la naturaleza con el pensamiento animista, llevándolas hasta sus últimas consecuencias.

${ }^{51}$ Sobre este tema, y para el caso de la Grecia antigua, leer combinadamente BORGEAUD, P., "El rústico", en J.-P. Vernant (ed.), El hombre griego, Madrid. Alianza Ed., 1993, p. 325-338; BUXTON, R., El imaginario griego, Madrid. Cambridge University Press, 2000, p. 88-97; y VEGETTI, M., “El hombre y los dioses”, en J.-P. Vernant (ed.), El hombre griego, Madrid. Alianza Ed., 1993 , p. $295-308$. 
entonces las conclusiones que se extrajeron para el primer tipo deberían poder transponerse al segundo. La sacralización de los animales fieros, de los territorios inhóspitos y de toda una serie de fenómenos naturales potencialmente catastróficos conlleva su reconocimiento como agentes responsables políticamente, en el sentido de que disponen de la capacidad para destruir y conformar espacios humanizados. Pero, por ese mismo motivo, escapan a toda relación de responsabilidad jurídica.

\section{Conclusiones}

El mérito de Nietzsche se halla en la identificación y crítica tanto de las premisas (relación enfermiza del hombre con su propia naturaleza, domesticación del individuo, gregarismo social y nivelación espiritual) como de las consecuencias finales del proceso de racionalización (colonización y domesticación de las potencialidades creativas, esto es, de todo espacio o momento disruptivo que escape al orden social establecido y pueda ser fuente de nuevas convenciones -nihilismo-). Aunque no anunciada expresamente en su obra, la destrucción del ambiente sería otra deriva más del desarrollo histórico de ese proceso de racionalización.

Pero, por otro lado, no se comparte con Nietzsche su reivindicación del individuo soberano, autónomo, temible, generador de caos y, también, de nuevas convenciones. Paradójicamente, ese proceso de racionalización al que el propio Nietzsche atribuye indeseables consecuencias se ha desplegado a través de la lógica del poder soberano: sintéticamente, es decir, a través de la suspensión del orden jurídico en situaciones en que un suceso es percibido como peligroso para la continuidad de la comunidad. En otras palabras, la racionalización ha avanzado gracias a la generación de ámbitos de irresponsabilidad jurídica respecto a los daños causados en los conflictos con otras comunidades y/o al ambiente, esto es, bajo la lógica de la dominación y la explotación ${ }^{52}$.

El problema de fondo en el planteamiento de Nietzsche reside en que su propuesta se asienta sobre la misma disociación y confrontación interna al propio individuo, de las diversas comunidades entre sí, y del ser humano con la naturaleza ${ }^{53}$, sólo que invierte el juicio de valoración: si el proyecto

\footnotetext{
52 Ver también HEIDEGGER, M., Nietzsche, tomo IV, Madrid, Ariel, [1961] 2013, p. 529ss.

53 desde el campo de la psicología, FREUD, S., El malestar en la cultura, Barcelona. Círculo de Lectores, 1999, también explica la individualidad y el proceso de racionalización desde la confrontación entre consciente e inconsciente.
} 
moderno justificaría la guerra sólo como un medio para restablecer un orden siempre precario, Nietzsche dice sí al conflicto (aunque reniegue de sus consecuencias históricas).

Frente a esas dos alternativas antagónicas, pero complementarias, creo que conviene redefinir el modo de articular las relaciones entre el ser humano y el ambiente, lo cual pasaría, a su vez, por redefinir el modo cómo comprendemos y nos relacionamos con nuestra instintividad ${ }^{54}$ y con aquellas otras comunidades políticas a las que tendemos a ver como amenazas latentes. Esta demanda de cambio se enfrenta a fuertes resistencias, pues apela al núcleo mismo de uno de nuestros instintos más básicos, como es el de supervivencia. La cuestión es que la senda histórica recorrida ha conducido a esa misma apelación: hoy en día, la pervivencia de la especie humana está amenazada, entre otros factores, como consecuencia de la crisis climática y ecológica ${ }^{55}$. Así pues, el dilema parece ser el siguiente: o bien aprendemos a controlar nuestra obsesión por el control y la seguridad, a adaptarnos y convivir con la diferencia cultural e, igualmente, con los peligros que generan las dinámicas autónomas de los ecosistemas (salvo excepciones, de gravedad limitada), o bien tratamos de continuar lidiando con las consecuencias, que se saben cada vez más graves, de la lógica expansionista y acumulativa inherente a los procesos de dominación y de explotación, así como de las dinámicas autonomizadas derivadas de los avances tecnológicos que subyacen en el proceso denominado “de racionalización”.

\footnotetext{
${ }^{54}$ Un planteamiento reciente alternativo al freudiano acerca de las relaciones entre consciente e inconsciente en BARGH, J.A., "Bypassing the will: toward desmytifying the nonconscious of social behavior" en Hassin, R.R.; Uleman, J.S.; Bargh, J.A. (eds.), The new unconscious, New York, etc., Oxford University Press, 2005.

55 JONAS, H., El principio de responsabilidad, Barcelona. Herder, [1979] 2004.
} 


\section{Bibliografía}

ACAMPORA, R., "Using and Abusing Nietzsche for Environmental Ethics,” Environmental Ethics, v. 16, n 2, 1994 , pp. 187-194.

AGAMBEN, G., Lo abierto. El hombre y el animal, Valencia. Pre-Textos, 2005.

AGAMBEN, G., Estado de excepción. Homo sacer II, 1, Valencia. Pre-Textos, 2004.

AGAMBEN, G., Homo sacer. El poder soberano y la nuda vida, Valencia. Pre-Textos, 1998.

BARGH, J.A., "Bypassing the will: toward desmytifying the nonconscious of social behavior" en R.R. Hassin; J.S. Uleman; J.A. Bargh (eds.), The new unconscious, New York, etc. Oxford University Press, 2005.

BORGEAUD, P., “El rústico”, en J.-P. Vernant (ed.), El hombre griego, Madrid. Alianza Ed., 1993, p. 325-338.

BUCKHARDT, J., Historia de la cultura griega, v. I, Madrid. RBA, 2005.

BUXTON, R., El imaginario griego, Madrid. Cambridge University Press, 2000.

CASCÓN, A., “Otra vez sobre Rómulo y Remo: Ciro y la leyenda del fundador”, Myrtia, no 31, 2016, 57-81.

CONWAY, D., "The birth of the State", en H. W. Siemens; V. Roodt (eds.), Nietzsche, power and politics: rethinking Nietzsche's legacy for political thought, Berlin; New York. Walter de Gruyter, 2008, p. 37-67.

DELEUZE, G., Nietzsche y la filosofia, 4a ed., Barcelona. Anagrama, [1967] 1994.

DRENTHEM, M., "Wildness as a critical border concept: Nietzsche and the debate on wilderness restoration", Environmental values, v. 14, nº 3, 2005, pp. 317-337.

DRENTHEM, M., "Nietzsche and the paradox of environmental ethics", New Nietzsche Studies, v. 5, n 1/2, 2002, p. $12-25$.

FINK, E., La filosofia de Nietzsche, Madrid. Alianza Ed., 1976.

FOUCAULT. M., Nietzsche, la genealogía, la historia, $7^{\text {a }}$ ed., Valencia. Pre-Textos, 2014.

FREUD, S., El malestar en la cultura, Barcelona. Círculo de Lectores, 1999.

GEMES, K.; JANAWAY, C., "Nietzsche on free will, autonomy and the sovereign individual”, en K. Gemes; S. May (eds.), Nietzsche on freedom and autonomy, Oxford. Oxford University Press, 2009, p. 33-50).

GENTILI, C., “Nietzsche: ¿político o apolítico?”, Estudios Nietzsche, Madrid. Trotta, no 12, 2012, p. 105-116.

HALLMAN, M., “Nietzsche’s Environmental Ethics”, Environmental Ethics, v. 13, nº 2, 1991, pp. 98-125.

HATAB, L., "Prospects for a democratic agon. Why we can still be Nietzscheans", Journal of Nietzsche Studies, $\mathrm{n}^{\circ}$ 24, 2002, pp. 132-147.

HATAB, L. J., A Nietzschean Defense of Democracy: An experiment in Postmodern Politics, Chicago. Open Court, 1995.

HEIDEGGER, M., Nietzsche, tomo IV, Madrid, Ariel, [1961] 2013.

HOBBES, T., De cive, Madrid. Alianza ed., 2000.

HOBBES, T., Leviathan, $2^{\text {a }}$ ed., Cambridge. Cambridge University Press, 1996.

HORKHEIMER, M.; ADORNO, T., Dialéctica de la ilustración, 2ª ed., Madrid. Trotta, [1969] 1997.

JONAS, H., El principio de responsabilidad, Barcelona. Herder, [1979] 2004.

KELSEN, H., Teoría pura del Derecho, $16^{\text {a }}$ ed., México, Ed. Porrúa, 2009.

LLINARES, M., “Lobishome. La metamorfosis en lobo en las tradiciones europea y gallega”, Memoria y civilización, $\mathrm{n}^{\mathrm{o}} 17,2004$, p. 123-148. 
LOZANO, F., "Los devoradores de hombres: el culto a Zeus Liceo y la licantropía en Arcadia", en Ferrer, E.; Marzuela, J.; Escacena, J. L. (coords.), De dioses y bestias: Animales y religión en el Mundo Antiguo, Sevilla. Universidad de Sevilla, 2008.

MORENO, M., "La naturaleza alterada. Imágenes de la metamorfosis animal en la antigua Grecia”, en M. Jufresa; M. Reig (eds.), Ta Zôia. L'espai a Grècia II: els animals i l'espai, Tarragona. SCEC-ICAC, 2011, p. 105-120.

NEHAMAS, A., "Nietzsche, intention, action”, European Journal of Philosophy, n 26, 2018, p. 685-701.

NIETZSCHE, F., Asi habló Zaratustra, $3^{\circ}$ ed., Alianza Ed., 2013.

NIETZSCHE, F., "El estado griego”, Ensayos sobre los griegos, Buenos Aires. Ediciones Godot, 2013, p. 7-25.

NIETZSCHE, F., La ciencia jovial, Madrid. Gredos, 2010.

NIETZSCHE, F., "Sobre verdad y mentira en sentido extramoral”, en F. Nietzsche, H. Vaihinger, Sobre verdad y mentira. $5^{\mathrm{a}}$ ed., Madrid. Tecnos, 2007, 3-22.

NIETZSCHE, F. "El crepúsculo de los ídolos", en Friedrich Nietzsche. Obras inmortales, vol. III, Madrid. Edicomunicación, 2003, p. 1285-1372.

NIETZSCHE, F., "De Schopenhauer como educador. Tercera consideración intempestiva", en Consideraciones intempestivas, 1873-76, Buenos Aires. Alianza, 2002, p. 97-215.

NIETZSCHE, F., El origen de la tragedia, 8ª ed., Madrid. Espasa-Calpe, 2000.

NIETZSCHE, F., La voluntad de poder, Madrid. Edaf, 2000.

NIETZSCHE, F., La genealogía de la moral, Madrid. Alianza Ed., 1997.

NIETZSCHE, F., Más allá del bien y del mal, Madrid. Alianza Ed.,1997.

NIETZSCHE, F., Aurora, Madrid. Edaf, 1996.

NIETZSCHE, F., Humano, demasiado humano, Madrid. Edaf, 1996.

NIETZSCHE, F., "La lucha de Homero", 1871-1872 (disponible en: http://190.186.233.212/filebiblioteca/Ciencias\%20Sociales/Friedrich\%20Nietzsche\%20-

\%20La\%20lucha\%20de\%20Homero.pdf, última consulta mayo de 2020).

OWEN, D., "Autonomy, self-respect, and self-love: Nietzsche on ethical agency", en K. Gemes; S. May (eds.), Nietzsche on freedom and autonomy, Oxford. Oxford University Press, 2009, p. 197-222.

PLATÓN, Diálogos IV. República, Madrid. Gredos, 2007.

QUESADA, J., "Nietzsche: risa, genealogía, carnaval. El teatro del<yo>”, en VVAA, Actualidad de Nietzsche: hacia nuevos horizontes. Michel Foucault: arqueología del poder y de las resistencias, Ciclos de conferencias sobre Michel Foucault i Nietzsche. La Coruña, abril 93-abril 94, La Coruña. Fundación Paideia, 1994, p. 51-66.

QUESADA, J., Un pensamiento intempestivo. Ontología, estética y política en F. Nietzsche, Barcelona. Anthropos, 1988.

RIDLEY, A., "Nietzsche, On art and freedom”, European Journal of Philosophy, 2007, v. 15, n 2, p. $204-224$.

RYKWERT, J., La idea de ciudad, Salamanca. Sígueme, 2002.

SANZ, R., "La política nietzscheana y la imagen de Grecia", en R. Sanz (coord.), Nietzsche: modernidad y política, Madrid. Dykinson, 2013, p. 105-149.

SCHILLER, F., La educación estética del hombre, Buenos Aires; etc, Espasa-Calpe, [1795]1943.

SMITH, M. S., Where the Gods are: spatial dimensions of anthropomorphism in the biblical world, New Haven; London. Yale University Press, 2016. 
STOREY, D.E., "Nietzsche and ecology revisited: the biological basis of value", Environmental ethics, v. 38, n 1 , 2016, pp. 19-45.

VAIHINGER, H., "La voluntad de ilusión en Nietzsche", en F. Nietzsche, H. Vaihinger, Sobre verdad y mentira. $5^{\mathrm{a}}$ ed., Madrid. Tecnos, 2007, 23-61.

Van INWAGEN, P.; SUlLIVAN, M., "Metaphysics", en Edward N. Zalta(ed.), The Stanford Encyclopedia of Philosophy, primavera 2018. <https://plato.stanford.edu/archives/spr2018/entries/metaphysics/> (última consulta: julio 2019).

VEGETTI, M., "El hombre y los dioses”, en J.-P. Vernant (ed.), El hombre griego, Madrid. Alianza Ed., 1993, p. 291321.

WISEMAN, P., "The God of the Lupercal”, The Journal of Roman Studies, v. 85, 1995, p. 1-22.

WHITROW, G. J., El tiempo en la historia. Barcelona. Crítica, 1990, p. 37-41.

WOORDWARD, A. (ed.), Interpreting Nietzsche: Reception and Influence, London, etc. Continuum, 2011. 